\title{
Decrements in neuromuscular performance and increases in creatine kinase impact training outputs in elite soccer players
}

\author{
Shane Malone \\ Technological University Dublin, Shane.Malone@TUDublin.ie \\ Bruno Mendes \\ Benfica Lab \\ Brian Hughes \\ Technological University Dublin, brian.hughes@tudublin.ie
}

See next page for additional authors

Follow this and additional works at: https://arrow.tudublin.ie/ittsciart

Part of the Medicine and Health Sciences Commons

\section{Recommended Citation}

Malone S, Mendes B, Hughes B, Roe M, Devenney S, Collins K, Owen A. Decrements in Neuromuscular Performance and Increases in Creatine Kinase Impact Training Outputs in Elite Soccer Players. J Strength Cond Res. 2018 May;32(5):1342-1351. doi: 10.1519/JSC.0000000000001997. PMID: 28557851.

This Article is brought to you for free and open access by the School of Science and Computing at ARROW@TU Dublin. It has been accepted for inclusion in Articles by an authorized administrator of ARROW@TU Dublin. For more information, please contact arrow.admin@tudublin.ie, aisling.coyne@tudublin.ie, gerard.connolly@tudublin.ie.

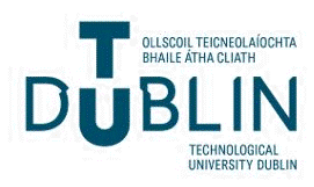




\section{Authors}

Shane Malone, Bruno Mendes, Brian Hughes, Mark Roe, Simon Devenney, Kieran Collins, and Adam Owen

This article is available at ARROW@TU Dublin: https://arrow.tudublin.ie/ittsciart/109 


\title{
Decrements in Neuromuscular Performance and Increases in Creatine Kinase Impact Training Outputs in Elite Soccer Players
}

\author{
Shane Malone, ${ }^{1,2}$ Bruno Mendes, ${ }^{2}$ Brian Hughes, ${ }^{1}$ Mark Roe, ${ }^{1}$ Simon Devenney, ${ }^{1}$ \\ Kieran Collins, ${ }^{1}$ and Adam Owen ${ }^{2,3}$ \\ ${ }^{1}$ Human Performance Lab, Institute of Technology Tallaght, Dublin, Ireland; ${ }^{2}$ Benfica Lab, S.L. Benfica, Lisbon, Portugal; \\ ${ }^{3}$ Center for Research and Innovation on Sport (CRIS), Claude Bernard University Lyon, Villeurbanne, France
}

\begin{abstract}
Malone, S, Mendes, B, Hughes, B, Roe, M, Devenney, S, Collins, K, and Owen, A. Decrements in neuromuscular performance and increases in creatine kinase impact training outputs in elite soccer players. J Strength Cond Res 32(5): 1342-1351, 2018-The aim of the current investigation was to understand the impact of pretraining neuromuscular performance and creatine kinase $(\mathrm{CK})$ status on subsequent training performance in elite soccer players. Thirty soccer players (age: $25.3 \pm 3.1$ years; height: $183 \pm 7 \mathrm{~cm}$; mass: $72 \pm 7 \mathrm{~kg}$ ) were involved in this observational study. Each morning before training, players completed assessments for neuromuscular performance (countermovement jump; CMJ) and CK levels. Global positioning technology provided external load: total distance, high-speed distance, sprint distance, accelerations, decelerations, average metabolic power, explosive distance, and high metabolic power distance $\left(>25.5 \mathrm{~W} \cdot \mathrm{kg}^{-1}\right)$. Mixed-effect linear models revealed significant effects for $\mathrm{CK}$ and $\mathrm{CMJ}$ Z-score on total high-speed distance, very high-speed distance, accelerations, decelerations, explosive distance, and maximal velocity. Effects are reported with $90 \%$ confidence limits. A CK Z-score of +1 corresponded to a $-5.5 \pm 1.1,-3.9 \pm 0.5,-4.3 \pm$ $2.9 \%,-4.1 \pm 2.9 \%,-3.1 \pm 2.9 \%$, and $-4.6 \pm 1.9 \%$, reduction in total high-speed distance, very high-speed distance, accelerations, decelerations, explosive distance, and maximal velocity, respectively. Countermovement jump Z-score of -1 corresponded to a $-3.5 \pm 1.1,-2.9 \pm 0.5,-2.1 \pm 1.4,-5.3$ $\pm 2.9 \%,-3.8 \pm 2.9 \%,-1.1 \pm 2.9 \%$, and $-5.6 \pm 1.2 \%$ reduction in these external load measures. Magnitude-based analysis revealed that the practical size of the effect of a pretraining CMJ Z-score of -1 and CK Z-score of +1 would have on total high-speed distance, very high-speed distance, high
\end{abstract}

Address correspondence to Shane Malone, shane.malone@mymail. ittdublin.ie.

$32(5) / 1342-1351$

Journal of Strength and Conditioning Research

(C) 2017 National Strength and Conditioning Association

1342

Journal of Strength and Conditioning Research metabolic power distance $\left(>25.5 \mathrm{~W} \cdot \mathrm{kg}^{-1}\right)$, accelerations, decelerations, explosive distance, and maximal velocity was likely negative. The results of this study suggest that systematic pretraining monitoring of neuromuscular and muscle stress within soccer cohorts can provide coaches with information about the training output that can be expected from individual players during a training session.

KEY WoRDS intermittent team sport, training monitoring, running performance, fatigue monitoring

\section{INTRODUCTION}

$\mathrm{T}$

he movement demands during soccer match play have been extensively reported $(24,28,31)$. Players typically cover distances of 9-14 km per match $(8,28)$, with most movement associated with lowintensity activities such as jogging and walking $(24,28)$. However, the outcome of a soccer match is heavily influenced by the high-speed components of play despite the game primarily taxing the aerobic system (32). Notably, $\sim 300$ acceleration and deceleration efforts (when categorized as changes in movement above $0.5 \mathrm{~m} \cdot \mathrm{s}^{-2}$ ) are performed per half (31) and $\sim 18 \%$ of the total distance covered during a soccer match is completed while accelerating or decelerating $(2,24)$. Within training environments, players have been shown to cover between 5 and $6 \mathrm{~km}$ with most distance covered at low intensity with intermittent bouts of accelerated movements $(2,21)$ The eccentric contributions required for these accelerated movements are likely to explain the physical distributions attributed to exercise induced muscular stress that are observed up to 120 hours post-match play $(22,23)$.

After training and match performance, a window of 72 hours is considered sufficient to achieve restoration in prematch and training values of physical performance benchmarks $(1,5)$. This recovery period, however, may not be afforded to teams competing in multiple competitions resulting in fixture congestion which is now, commonplace professional soccer. The resultant effect is insufficient recovery 
and/or possible decrements in both match-play and training performance $(27,30)$. It would therefore seem important within a periodized training structure that estimates of match-related fatigue are determined, particularly between matches where alleviating post-match fatigue, regaining performance levels and minimizing injury risk are deemed crucial to team's overall performance levels $(22,23,27)$.

Previously countermovement jump (CMJ) and creatine kinase $(\mathrm{CK})$ concentrations have been reported within the literature as markers to assess the influence of previous exercise on subsequent performance $(23,32)$. Indeed Russell et al. (32) examined 4 competitive matches and reported reductions in $\mathrm{CMJ}$ and peak power output ( +24 hours: 237 $\pm 170 \mathrm{~W},+48$ hours: $98 \pm 168 \mathrm{~W}$ ) after 90 minutes of soccer match play. This investigation also reported elevation of $\mathrm{CK}$ 24 hours post-match play ( +24 hours: $+334.8 \pm 107.2$ $\mu \cdot \mathrm{L}^{-1}$ ) with further elevation 48 hours post competition $\left(+48\right.$ hours: $\left.+156.9 \pm 121.0 \mu \cdot \mathrm{L}^{-1}\right)$. These responses were found to be consistent across positions and all match play environments. Furthermore, players with increased lower

TABLE 1. Load and Intensity Measures for all training sessions. Data presented as Mean $( \pm)$ $S D .^{*}$

Load measures

Total distance $(\mathrm{m})$

Total high-speed distance $(\mathrm{m})$

Very high-speed distance $(\mathrm{m})$

Accelerations ( $n$ )

Decelerations (n)

High-power distance (m)

Dynamic stress load (AU)

Impacts ( $\mathrm{n}$ )

Maximum velocity $\left(\mathrm{km} \cdot \mathrm{h}^{-1}\right)$

Session intensity

Session duration

Session RPE

Relative session distance $\left(\mathrm{m} \cdot \mathrm{min}^{-1}\right)$

Total high-speed distance per minute $\left(\mathrm{m} \cdot \mathrm{min}^{-1}\right)$

Very high-speed distance per minute $\left(\mathrm{m} \cdot \mathrm{min}^{-1}\right)$

Accelerations per minute $\left(\mathrm{a} \cdot \mathrm{min}^{-1}\right)$

Decelerations per minute

$\left(d \cdot \min ^{-1}\right)$

High-power distance

per minute $\left(\mathrm{m} \cdot \mathrm{min}^{-1}\right)$

Dynamic stress load per minute

$\left(\mathrm{AU} \cdot \mathrm{min}^{-1}\right)$

Impacts per minute $\left(\mathrm{m} \cdot \mathrm{min}^{-1}\right)$

Average metabolic power

$\left(\mathrm{W} \cdot \mathrm{Kg}^{-1}\right)$ limb strength characteristics have been shown to have reduced CK 48 hours post-match play (25). Interestingly, moderate relationships between match-play activities, CK elevation, and $\mathrm{CMJ}$ reductions have been observed in professional soccer players (32), with high-intensity activity related to the change in $\mathrm{CK}$ and $\mathrm{CMJ}$ within 15 professional players.

Although match-play relationships are interesting to practitioners, currently practitioners are concerned with the best preparation of players to maximize physical performance output within match-play environments. Previously, matchplay performance characteristics have been used to predict and individualize recovery within a number of team sporting settings $(17,22,36)$. However, the between match variation in these measures do not lend them to accurately fully understand the necessary recovery required of players. Although between match recovery is an important consideration, for peak match-play performance the prescription of the appropriate training is required; therefore, the between training session recovery and within session content become paramount to coaches. Therefore, objective markers of lower limb fatigue and muscular stress offer an important insight to coaches to manipulate training content to best ensure preparedness of players to perform, within specific training and match-play environments. The responses of $\mathrm{CMJ}$ and $\mathrm{CK}$ to match-play activities are currently well understood; however, there is a lack of understanding of the impact that reductions in $\mathrm{CMJ}$ and elevations in CK have on training outputs within soccer players. Therefore, the current investigation aimed to understand the effect that elevated CK or reductions in CMJ pretraining-impacted players training output with elite professional soccer players. It was expected that elevated CK and reductions in CMJ would result in a reduction in high-speed activities during training environments.

\section{MeTHODS}

\section{Experimental Approach to Problem}

The current observational investigation aimed to understand the effect that elevated $\mathrm{CK}$ or reductions in $\mathrm{CMJ}$ pretraining-impacted players' training output with that of elite professional soccer players using global positioning satellite systems $(10-\mathrm{Hz}$, Viper Pod; STATSports, Abbey Way, Newry, Northern Ireland) to monitor training outputs. The study period involved all training sessions during the $2015 / 2016$ season. In total, 30 players participated in 240 training sessions resulting in 7,200 individual sessions which were examined. Participants had been familiarized to all experimental protocols as these were part of day-to-day practice. Before each training session, players completed a $\mathrm{CMJ}$ and $\mathrm{CK}$ assessments for the identification of neuromuscular fatigue and muscular stress.

\section{Subjects}

The current investigation was a prospective observation study of elite soccer players competing for a team who at the time of data collection were competing at the highest level of 
European competition (Liga NOS and Champions league) for the duration of the current investigation. Data were collected for 30 players (Mean $\pm S D$, age: $25.3 \pm 3.1$ years; height: $183 \pm 7 \mathrm{~cm}$; mass: $72 \pm 7 \mathrm{~kg}$ ) over 1 season. The study was approved by the Institute of Technology, Tallaght's research ethics committee and written informed consent was obtained from each participant. The study period involved all training sessions during the 2015/2016 season.

\section{Procedures}

Monitoring of Training Session Movement Demands. During training sessions all movements were monitored. The players' physical activity during each training session was monitored using a portable nondifferential $10-\mathrm{Hz}$ global positioning system technology (GPS) integrated with a $100-\mathrm{Hz}, 3$-dimensional accelerometer, 3-dimensional gyroscope, and a 3-dimensional digital compass (STATSports Viper Pod). This type of system has previously been shown to provide valid and reliable estimates of instantaneous velocity during acceleration, deceleration, and constantvelocity movements during linear, multidirectional, and soccer-specific activities (35). Each player was assigned a particular vest that was tightly fitted to their upper torso, holding the receiver between the scapulae. All devices were always activated 15 minutes before the data collection to allow acquisition of satellite signals in accordance with the manufacturer's instructions (10). In addition, to avoid interunit error, each player wore the same GPS device for each training session (35). After recording, the data were downloaded to a computer and analyzed using the software package Viper version 3.2 (STATSports, 2012). Based on GPS data, total high-speed $\left(>14.4 \mathrm{~km} \cdot \mathrm{h}^{-1}\right)$ and very highspeed $\left(>19.8 \mathrm{~km} \cdot \mathrm{h}^{-1}\right)$ running distance were calculated during each training session. Total high-speed and very high-speed running distance covered were also divided by session duration (minute) to obtain the intensity values per minute. These measures are reflective of standardized measures of training load regularly reported within soccer cohorts $(2,4,5,8,9)$.

Acceleration and Deceleration. Acceleration and deceleration activity have previously been shown to increase both muscular stress $(31,32)$ and the energetic demands $(2,24)$ within soccer cohorts and reflect the subtle movements within soccer training and match-play contexts. Acceleration was measured on the basis of the change in GPS speed data and was defined as a change in speed for a minimum period of 0.5 seconds with a maximum acceleration in the period at least $0.5 \mathrm{~m} \cdot \mathrm{s}^{-2}$. The acceleration was considered finished when the player stopped accelerating. The classification of accelerations by zone is based on the maximum acceleration reached in the acceleration period. The same approach was used with regard to deceleration. The load and intensity measures were identified as total number of accelerations or decelerations $\left(>3 \mathrm{~m} \cdot \mathrm{s}^{-2}\right)$ and accelerations or decelerations per minute, respectively.

Metabolic Power. Gaudino et al. $(12,13)$ have shown a systematic bias between high-speed running and metabolic power

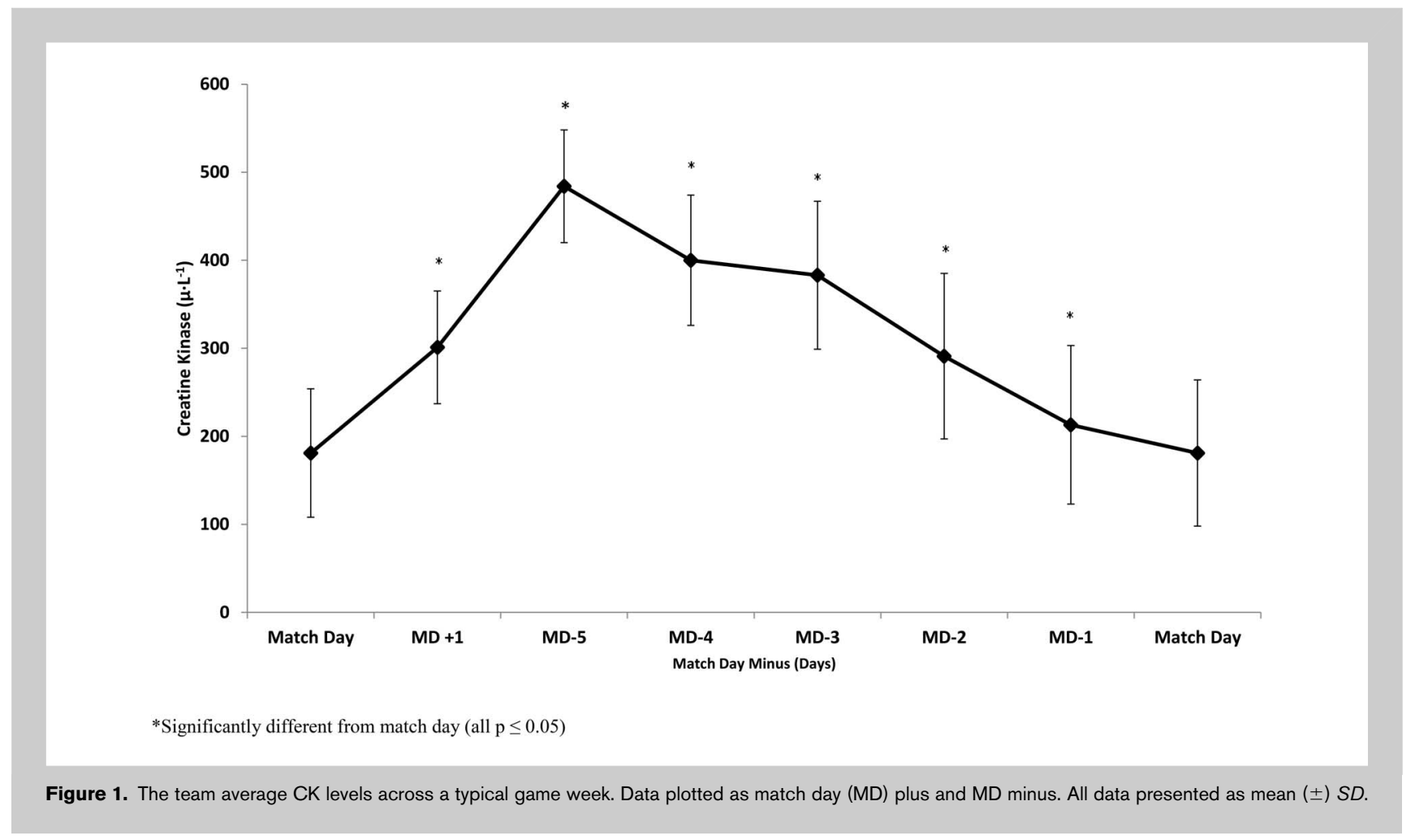




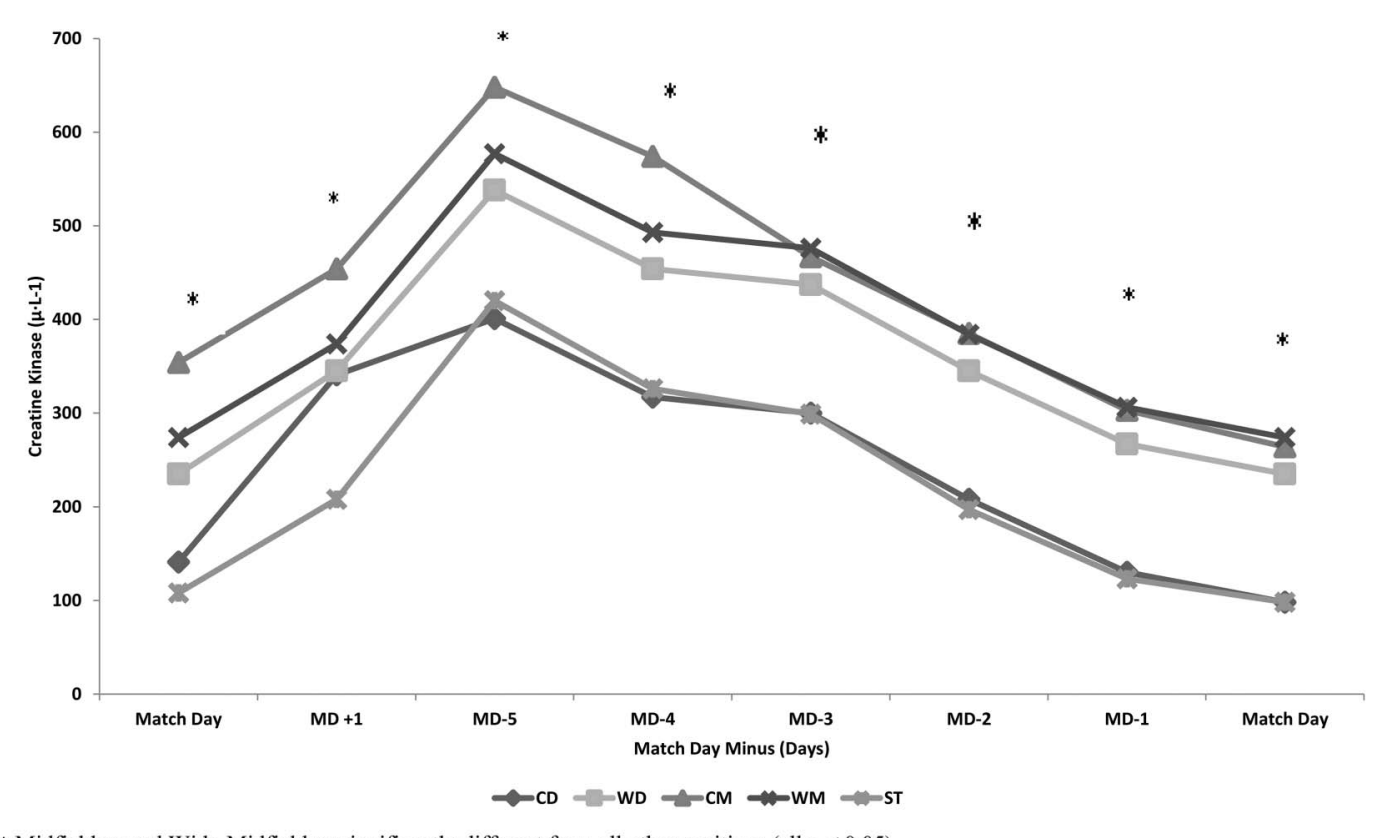

* Midfielders and Wide-Midfielders significantly different from all other positions (all $\mathrm{p} \leq 0.05$ )

Figure 2. The positional profile of CK levels across a typical training week. Data presented as mean $\pm S D$.

within drills showing that metabolic power can better reflect the physiological demands of training within soccer cohorts. During this study, average metabolic power $\left(\mathrm{W} \cdot \mathrm{kg}^{-1}\right)$ was estimated as previously described $(9,12,13)$ and identified as load and intensity measures, respectively. Consequently, distance covered at metabolic power $>25.5 \mathrm{~W} \cdot \mathrm{kg}^{-1}$ (high metabolic power) was analyzed as an indicator of the highintensity distance covered $(12,13)$. A power of 25.5 $\mathrm{W} \cdot \mathrm{kg}^{-1}$ corresponds to when a player is running at a constant speed of approximately $5.5 \mathrm{~m} \cdot \mathrm{s}^{-1}$ (i.e., $19.8 \mathrm{~km} \cdot \mathrm{h}^{-1}$ ) on grass or performing significant acceleration or deceleration activity, for example, if accelerating from 2 to 4 $\mathrm{m} \cdot \mathrm{s}^{-1}$ over 1 second (i.e., an acceleration equal to $2 \mathrm{~m} \cdot \mathrm{s}^{-2}$ ). The load and intensity measures were identified as high metabolic power distance and high metabolic power distance per minute, respectively.

Dynamic Stress Load. Dynamic stress load was calculated as the total of the weighted impacts. Impacts were weighted using convex-shaped function (approximately a cubic function), an approach similar to the one used in the speedintensity calculation, with the key concept being that an impact of $4 \mathrm{~g}$ is more than twice as hard on the body as an impact of $2 \mathrm{~g}$. The weighted impacts were aggregated and

TABLE 2. The $R^{2}$ of the linear models for each running performance variable, $Z$-score coefficient and $p$-value of the fixed effect test on CK Z-score.

\begin{tabular}{lccc}
\hline Training output variables & $R^{2}$ & Coefficient $\pm 90 \% \mathrm{CL}$ & $p$ \\
\hline Total distance $(\mathrm{m})$ & 0.35 & $0.02 \pm 0.03$ & 0.215 \\
Total high-speed distance (m) & 0.31 & $0.07 \pm 0.04$ & $0.019^{\star}$ \\
Very high-speed distance (m) & 0.31 & $0.07 \pm 0.04$ & $0.019^{\star}$ \\
High-power distance (m) & 0.65 & $0.08 \pm 0.03$ & $0.021^{\star}$ \\
Total accelerations (n) & 0.42 & $0.09 \pm 0.03$ & $0.011^{\star}$ \\
Total decelerations (n) & 0.42 & $0.09 \pm 0.03$ & $0.011^{\star}$ \\
Explosive distance (m) & 0.59 & $0.15 \pm 0.09$ & $0.005^{\star}$ \\
Maximal velocity $\left(\mathrm{km} \cdot \mathrm{h}^{-1}\right)$ & 0.43 & $0.16 \pm 0.08$ & $0.012^{\star}$ \\
\hline
\end{tabular}

${ }^{*}$ Significant effect during fixed effect testing $(p<0.05)$. 
TABle 3. The size (d) magnitude descriptor and qualitative inference of the effect of a Z-score of +1 for CK on training running performance.

\begin{tabular}{lccc}
\hline Training output variables & $d \pm 90 \% \mathrm{CL}$ & Descriptor & Qualitative inference \\
\hline Total distance $(\mathrm{m})$ & $0.13 \pm 0.02$ & Small & Trivial \\
Total high-speed distance $(\mathrm{m})$ & $-0.73 \pm 0.02$ & Moderate & Likely negative \\
Very high-speed distance $(\mathrm{m})$ & $-0.73 \pm 0.02$ & Moderate & Likely negative \\
High-power distance $(\mathrm{m})$ & $-0.60 \pm 0.19$ & Moderate & Likely negative \\
Total accelerations $(\mathrm{n})$ & $-0.89 \pm 0.19$ & Moderate & Likely negative \\
Total decelerations $(\mathrm{n})$ & $-0.89 \pm 0.19$ & Moderate & Likely negative \\
Explosive distance $(\mathrm{m})$ & $-1.01 \pm 0.33$ & Moderate & Most likely negative \\
Maximal velocity $\left(\mathrm{km} \cdot \mathrm{h}^{-1}\right)$ & $-1.26 \pm 0.28$ & Moderate & Most likely negative \\
\hline
\end{tabular}

finally scaled to give more workable values expressed in arbitrary units (AUs). The load and intensity measures were identified as dynamic-stress load and dynamic-stress load per minute, respectively. Dynamic-stress load was calculated automatically using a custom algorithm included in the proprietary software provided by the manufacturers (Viper Version 3.2, STATSports).

Neuromuscular Fatigue and Muscle Stress Assessments. Before each training session, players completed a CMJ and CK assessments. Players were first assessed for $\mathrm{CK}$ in a rested state before completing a CMJ assessment (Optogait, Microgate, Bolzano, Italy). The players then performed 6 repetitions of a CMJ. The CMJs were performed with hands held firmly on the hips and subjects were instructed to jump as high as possible. All jumps were performed at a self-selected countermovement depth and no instruction was given on what countermovement depth to use; the mean of the 6 repetitions was used as a representation of players pretraining neuromuscular characteristics. Blood $\mathrm{CK}$ was assessed as an indirect marker of muscle damage at the same time points as neuromuscular fatigue. After prewarming of the hand, a $30-\mu \cdot \mathrm{L}^{-1}$ sample of blood was taken using the fingertip and analyzed using a colorimetric assay procedure (Reflotron; Boehringer, Mannheim, Germany). Before each testing session, the instrument was calibrated in accordance with manufacturer recommendations. The typical error for CK was $2.3 \%$. Overall $\mathrm{CK}$ and CMJ scores were reported relative to individual's absolute average and nor-

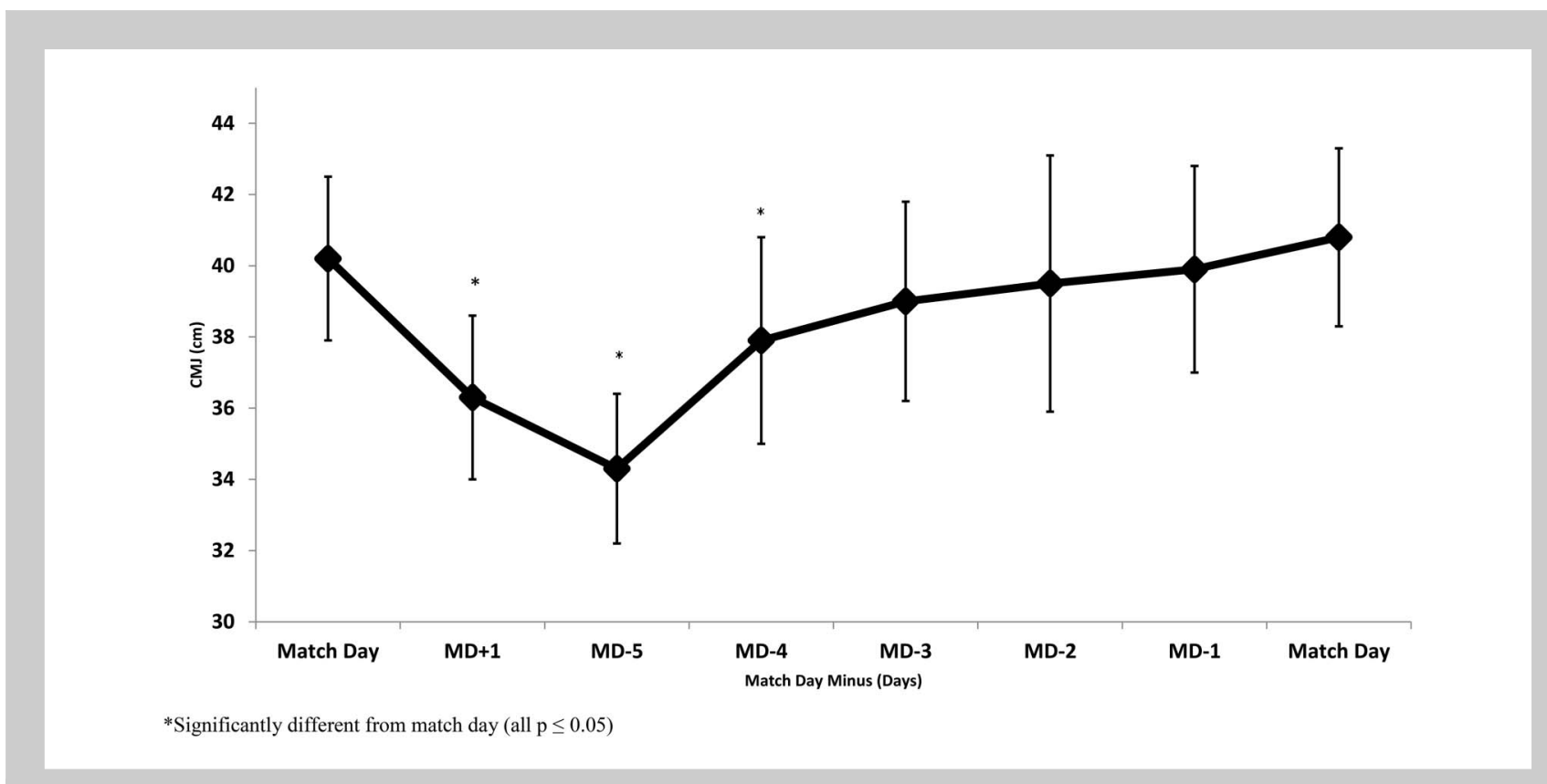

Figure 3. The team mean of $6 \mathrm{CMJ}$ performance across a typical training week. Data presented as mean $\pm S D$. CMJ $=$ countermovement jump. 


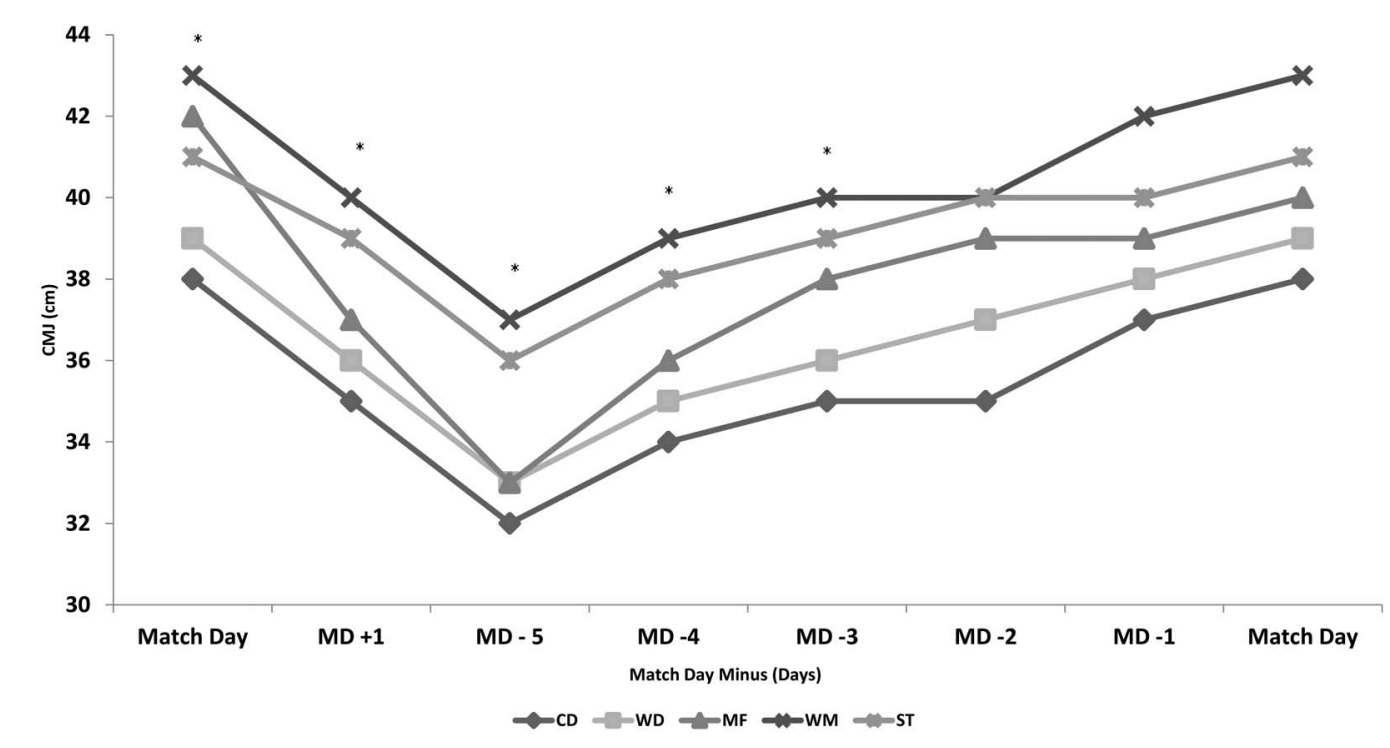

*Wide-Defender, Midfielders and Wide-Midfielders significantly different from all other positions (all $\mathrm{p} \leq 0.05$ )

Figure 4. The positional profile of CMJ performance across a typical training week. Data presented as mean $\pm S D$. CMJ $=$ countermovement jump.

mal variation from the duration of the season by reporting them as Z-scores. To use Z-scores, only data from individual $\mathrm{s}$ whose $\mathrm{CK}$ and $\mathrm{CMJ}$ scores were deemed normally distributed were used (26). Calculated using the following formula: (individual players score - individual players average)/individual players standard deviation, a $Z$-score is the number of standard deviations the response is above or below the mean of the distribution.

\section{Statistical Analyses}

To examine the effect of $\mathrm{CK}$ and CMJ Z-score on the movement patterns of players during subsequent training session parameters, mixed-effect linear models were performed using the statistical software R (Version 3.0.1). To control the differences in training output seen between playing positions and prescribed load between training sessions, players were categorized as per their role in the team with position and session entered as random effects. $\mathrm{CK}$ and $\mathrm{CMJ} Z$-score was entered as the fixed effect. The load parameters were log-transformed to report the change in the parameters as a percentage change per $1 \mathrm{Z}$-score wellness change. The coefficient of CK and CMJ Z-score \pm $90 \% \mathrm{CL}$ was then taken as the value of the effect of wellness on load within a session. To examine the relationship between external load, CK, and CMJ Z-score, mixed-effect linear models were performed with subject entered as the

TABLE 4. The $R^{2}$ of the linear models for each running performance variable, model intercept, Z-score coefficient and $p$-value of the fixed effect test on CMJ Z-score.

\begin{tabular}{lccc}
\hline Training output variables & $R^{2}$ & Coefficient $\pm 90 \% \mathrm{CL}$ & $p$ \\
\hline Total distance (m) & 0.35 & $0.02 \pm 0.03$ & 0.125 \\
High-speed distance (m) & 0.41 & $0.07 \pm 0.04$ & $0.039^{\star}$ \\
Very high-speed distance (m) & 0.41 & $0.07 \pm 0.04$ & $0.039^{\star}$ \\
High-power distance (m) & 0.45 & $0.08 \pm 0.03$ & $0.031^{\star}$ \\
Total accelerations (n) & 0.39 & $0.09 \pm 0.03$ & $0.041^{\star}$ \\
Total decelerations (n) & 0.39 & $0.09 \pm 0.03$ & $0.041^{\star}$ \\
Explosive distance (m) & 0.41 & $0.15 \pm 0.09$ & $0.035^{\star}$ \\
Maximal velocity $\left(\mathrm{km} \cdot \mathrm{h}^{-1}\right)$ & 0.40 & $0.16 \pm 0.08$ & $0.022^{\star}$ \\
\hline
\end{tabular}

*Significant effect during fixed effect testing $(p<0.05)$. 
random effect Significance was set at the $P<0.05$ level. The magnitudes of the effects were reported as Cohen's effect sizes (d) with $\mathrm{d} \pm 90 \% \mathrm{CL}$ described as $<0.2$ trivial, $0.2-$ 0.6 small, $0.6-1.2$ moderate, $1.2-2.0$ large, $2.0-4.0$ very large (6). The qualitative interpretation that the true value of the effect represented an important change was determined with magnitude-based inferences as $<75 \%$ trivial, $\geq 75 \%$ likely, $>95 \%$ very likely, $>99.5 \%$ almost certainly that the effect size exceeded $0.20(3,15)$. An effect where there was $>5 \%$ chance of the change being positive or negative was deemed as unclear.

\section{RESUlts}

The average training performance data are presented in Table 1 . The average duration of training was $75 \pm 15 \mathrm{mi}-$ nutes, with the average total distance during training was $5,438 \pm 1,884 \mathrm{~m}$, with an average metabolic power of 6.7 $\pm 2.0 \mathrm{~W} \cdot \mathrm{kg}^{-1}$ and an acceleration and deceleration profile of $35 \pm 12$ and $32 \pm 15$, respectively. The average weekly internal load was $427 \pm 92 \mathrm{AU}$.

Compared with the match day there was a very likely increase in CK from match day to MD-5, with likely day-today decreases in CK across the week until the subsequent match day (Figure 1). Specifically, there was a possibly-tolikely large elevation in $\mathrm{CK}$ at 24 hours $(314.8 \pm 107.2$ $\mu \cdot \mathrm{L}^{-1}$; possibly large; $\left.p=0.04\right)$ and 48 hours $(484.4 \pm$ 176.8.0 $\mu \cdot \mathrm{L}^{-1}$; likely large; $p=0.001$ ) post-match play. There was a positional profile for $\mathrm{CK}$ with midfielders having very likely higher CK levels across weekly periods (Figure 2).

Table 2 shows the mixed-effect linear models reporting the impact a reduction in CK Z-score of -1 had on training output variables. A CK Z-score of +1 corresponded to a $-5.5 \pm 1.1,-3.9 \pm 0.5,-2.1 \pm 1.4,-4.3 \pm 2.9 \%$, $-4.1 \pm 2.9 \%,-3.1 \pm 2.9 \%$, and $-4.6 \pm 1.9 \%$, reduction in total high-speed distance $\left(R^{2}=0.31\right.$; coefficient $\pm 90 \%$ CL: $0.07 \pm 0.04 ; p=0.019)$, very high-speed distance $\left(R^{2}=0.31\right.$; coefficient $\pm 90 \%$ CL: $0.07 \pm 0.04 ; p=0.019)$, high-power distance $\left(R^{2}=0.65\right.$; coefficient $\pm 90 \%$ CL: $0.08 \pm 0.03$; $p=$
$0.021)$, total accelerations $\left(R^{2}=0.42\right.$; coefficient $\pm 90 \%$ CL: $0.09 \pm 0.03 ; p=0.011)$, total decelerations $\left(R^{2}=0.42\right.$; coefficient $\pm 90 \%$ CL: $0.09 \pm 0.03$; $p=0.011$ ), explosive distance $\left(R^{2}=0.59\right.$; coefficient $\pm 90 \%$ CL: $0.15 \pm 0.09$; $p=0.005)$ and maximal velocity $\left(R^{2}=0.43\right.$; coefficient $\pm 90 \%$ CL: $0.16 \pm 0.08 ; p=0.012$ ), respectively, compared with those without increased CK (Table 2). Magnitudebased analysis revealed that the practical size of the effect of a pretraining CMJ Z-score of -1 would have on total high-speed distance $(d=-0.73$; moderate), very highspeed distance $(d=-0.73$; moderate), high-power distance $(d=-0.60$; moderate), total accelerations $(d=-0.89$; moderate), total decelerations $(d=-0.89$; moderate), explosive distance $(d=-1.01$; large), and maximal velocity $(d=$ -1.26 ; large) was likely to most likely negative (Table 3 ).

Compared with match day, there was a likely decrease in CMJ from match day to MD-5, with possibly likely day-today increases in CMJ from MD-5 onward across the week until the subsequent match day (Figure 3). Specifically, there was a possibly moderate to possibly large reduction in CMJ at 24 hours $(36.3 \pm 4.2 \mathrm{~cm}$; possibly moderate; $p=0.032)$ and 48 hours $(33.4 \pm 4.8 \mathrm{~cm}$; possibly large; $p=0.001)$ postmatch play. There was a positional profile for CMJ with midfielders having very likely higher reduction in $\mathrm{CMJ}$ post-match day (Figure 4).

The effect of a CMJ Z-score of -1 corresponded to a $-3.5 \pm 1.1,-2.9 \pm 0.5,-2.1 \pm 1.4,-5.3 \pm 2.9 \%$, $-3.8 \pm 2.9 \%,-1.1 \pm 2.9 \%$, and $-5.6 \pm 1.2 \%$, reduction in total high-speed distance $\left(R^{2}=0.41\right.$; coefficient $\pm 90 \% \mathrm{CL}$ : $0.07 \pm 0.04 ; p=0.039)$, very high-speed distance $\left(R^{2}=0.41\right.$; coefficient $\pm 90 \%$ CL: $0.07 \pm 0.04 ; p=0.039$ ), HP distance $\left(R^{2}=0.45\right.$; coefficient $\pm 90 \%$ CL: $\left.0.08 \pm 0.03 ; p=0.031\right)$, total accelerations $\left(R^{2}=0.39\right.$; coefficient $\pm 90 \%$ CL: $0.09 \pm$ $0.03 ; p=0.041)$, total decelerations $\left(R^{2}=0.39\right.$; coefficient $\pm 90 \%$ CL: $0.09 \pm 0.03 ; p=0.041)$, explosive distance $\left(R^{2}=\right.$ 0.41 ; coefficient $\pm 90 \%$ CL: $0.15 \pm 0.09 ; p=0.035)$, and maximal velocity $\left(R^{2}=0.40\right.$; coefficient $\pm 90 \%$ CL: $0.16 \pm$ $0.08 ; p=0.022$ ), respectively (Table 4). Magnitude-based analysis revealed that the practical size of the effect of

TABLE 5. The size ( $d$ ) magnitude descriptor and qualitative inference of the effect of a Z-score of -1 for CMJ performance on training running performance.

\begin{tabular}{lccc}
\hline Training output variables & $d \pm 90 \% \mathrm{CL}$ & Descriptor & Qualitative inference \\
\hline Total distance $(\mathrm{m})$ & $0.13 \pm 0.02$ & Small & Trivial \\
High-speed distance $(\mathrm{m})$ & $-0.53 \pm 0.12$ & Moderate & Likely negative \\
Very high-speed distance $(\mathrm{m})$ & $-0.53 \pm 0.12$ & Moderate & Likely negative \\
High-power distance $(\mathrm{m})$ & $-0.59 \pm 0.21$ & Moderate & Likely negative \\
Total accelerations $(\mathrm{n})$ & $-0.69 \pm 0.29$ & Moderate & Likely negative \\
Total decelerations $(\mathrm{n})$ & $-0.69 \pm 0.29$ & Moderate & Likely negative \\
Explosive distance $(\mathrm{m})$ & $-0.79 \pm 0.33$ & Moderate & Likely negative \\
Maximal velocity $\left(\mathrm{km} \cdot \mathrm{h}^{-1}\right)$ & $-1.26 \pm 0.18$ & Moderate & Most likely negative \\
\hline
\end{tabular}


a pretraining $\mathrm{CMJ}$ Z-score of -1 would have on total highspeed distance $(d=-0.53$; small), very high-speed distance ( $d=-0.60$; moderate), high-power distance $(d=-0.63$; moderate), total accelerations $(d=-0.69$; moderate), total decelerations $(d=-0.69$; moderate), explosive distance $(d=$ -0.79 ; moderate), and maximal velocity $(d=-1.26$; large) was likely to most likely negative (Table 5).

\section{Discussion}

The aim of the current investigation was to observe the impact that pretraining neuromuscular performance and CK status had on training performance within elite soccer players; the results show that elite soccer training output can be influenced by reduced neuromuscular performance and increased CK levels as determined by Z-scores. We found that training performance was reduced when players experienced $\mathrm{a}+1 \mathrm{Z}$-score increase in $\mathrm{CK}$ with likely to most likely reductions in total high-speed distance, very highspeed distance, HP distance, accelerations, decelerations, explosive distance, and maximal velocity, respectively, compared with those without $+1 \mathrm{Z}$-score increases. Similar trends were observed for $-1 \mathrm{Z}$-score reductions in $\mathrm{CMJ}$ with those players who experienced this neuromuscular decrements pretraining having a reduction in total high-speed distance, very high-speed distance, HP distance, accelerations, decelerations, explosive distance, and maximal velocity, respectively.

While different teams may utilize different GPS systems for the analysis of movement demands, an analysis of the representativeness of the training loads completed by the players in this study is important. The overall training schedule and training session duration in our research was similar to those observed in English professional soccer teams during the in-season periods (20). In terms of external load measures, the relative distance values in this study averaged $72.5 \mathrm{~m} \cdot \mathrm{min}^{-1}$. Such values were $8.1 \%$ higher than those reported in an elite senior English soccer team, with average values of $66.6 \mathrm{~m} \cdot \mathrm{min}^{-1}$ across the in-season period (20). The amount of high-speed distance covered was also $28.9 \%$ higher in this study (mean, $414 \mathrm{~m}$ ) in comparison with that of the elite senior English soccer players (mean, $119 \mathrm{~m}$ ) $(12,13)$ using the same velocity banding. When taken together, it seems that the training loads used in elite soccer vary depending on the country of competition. This may be due to the emphasis on different coaching points and styles of play between European countries.

Consistent with previous research $(33,34)$ we observed large increases in CK peaking 24 hours post-match with CK being at its highest 48 hours post-match. Interestingly, there were consistent reductions in $\mathrm{CK}$ as the training week progressed. In the current study, pre-match to post-match muscle damage were comparable with those of previous research that studied soccer and other intermittent sports $(7,18)$. The time course changes observed by these investigations would suggest that the players in this study would still be in a state of recovery for 72 hours post-match. Therefore, the findings would seem relevant to many coaches. With players still in a state of recovery 72 hours postmatch play it would seem that training should be structured to reflect this recovery process to ensure that players are at reduced risk of injury. It is inferred that $\mathrm{CK}$ and its relationship with muscle damage is a developing area for research to determine individual recovery strategies. A study by Young et al. (36) revealed significant correlations between $\mathrm{CK}$ and running speeds $>4 \mathrm{~m} \cdot \mathrm{s}^{-1}$ and accelerations and decelerations over a certain magnitude (moderate to high). Furthermore, it was suggested that may be a certain volume of movement at those speeds is required for that movement to be strongly associated with CK levels. In addition, when leaked into circulation in response to the manifestation of microtrauma (muscle damage) to structural and contractile components within the muscle fiber, $\mathrm{CK}$ serum activity has been proposed to mirror the high mechanical muscular stress experienced during intensive exercise performance (19). Interestingly, a positional profile was identified for CK across the typical training week with central midfield players were shown to have the highest $\mathrm{CK}$ levels across the week. Previously, Malone et al. (20) reported central midfield highest total distance, with CD players displaying the lowest values for total distance. Interestingly, we observed that central defenders displayed the lowest CK values within this current investigation. Such differences between positions are not uncommon in elite soccer, with the findings in the current study also replicated in positional match-play data (4). Our data showed that increased CK pretraining as reported by an increase in Z-Score by +1 has a subsequent impact on players' ability to engage in high-speed movements within the training environment. As a result, this has significant practical implications for coaches, as players with increased $\mathrm{CK}$ are not able to train or achieve the movement demands required to achieve the optimum performance within match-play and thus may be at an increased risk of injury within the training environment or within subsequent match-play scenarios (21). Players with elevated CK levels may as such engage in shortened sessions or specific modified training scenarios that allow for their specific positional intensity to be achieved without increased training volume being imposed on these players.

The assessment of neuromuscular status after intense exercise is important to understand the physiological impact of a given training stimulus (14). The current study measured neuromuscular status through CMJ assessment and observed that reductions in $\mathrm{CMJ}$ performance peaked immediately post game, with these slowly returning to pre-match levels as the training week progressed. These findings are in line with previous observations in other intermittent field sports (16). Interestingly, the sensitivity of this measure has previously been questioned in soccer cohorts (20) however within the current investigation $\mathrm{CMJ}$ performance was sensitive to match play and was also shown to impact subsequent 
training performance within elite professional soccer players. Therefore, coaches should use data collected through CMJ assessment to plan subsequent training loads. Coaches may alter the physical focus of training based on these results. Typically, within soccer cohorts training load prescription during the in-season period will predominantly relate to the maintenance of fitness levels and ensuring that players are fully recovered in between competitive matches $(28,29)$. Soccer coaches therefore seem to typically use training loads that preserve fitness (i.e., external training load that maximizes recovery while maintaining current physiological status) (20) and have a tactical focus as opposed to designing training stresses that attempt to physiologically overload the players for fitness improvement. However, if repetitive loading patterns are repeated longitudinally during the season, then the chance of training monotony and subsequent risk of injury/maladaptation may increase (11). Therefore, it is important that soccer practitioners quantify training load longitudinally while also monitoring the performance response across each individual player to best modify players' training load to ensure these maladaptive responses do not take place. Modification of players' training load can take place by reducing the players' training time within a session or through allowing the player to complete a specifically tailored training session to the specific positional needs of the player best allowing for the player to attain the positional intensity during the training at a reduced volume of training load. Within the current investigation, CMJ assessment seems to offer a practical assessment for coaches to implement to understand the dose response of training sessions and how that can impact subsequent player physical outputs.

\section{Practical Applications}

The results of the current study suggest that systematic monitoring of neuromuscular and muscle damage status within elite soccer cohorts can provide coaches with information about the training output that can be expected from individual players during a training session. Within the current investigation CMJ assessment seems to offer a practical assessment for coaches to implement to understand the dose-response of training sessions. For example associations between elevated CK and reduced CMJ levels have been shown with likely to most likely negative effects on players' ability to achieve total high-speed distance, very high-speed distance, HP distance, accelerations, decelerations, explosive distance, and maximal velocity. This has practical implications for coaches as players with increased CK may not able to train to the required level and thus may be at increased risk of injury within the training environment, subsequently these players may be at increased risk of injury within match-play scenarios because of reduced recovery as shown by increased CK markers. Altogether these findings show that increases in muscular damage and reductions in neuromuscular performance can result in decrements in training session outputs that may overtime lead to maladaptive responses and increase these players' subsequent injury risk. From these data, coaches may adapt and modify players' load within training based on pre-session $\mathrm{CMJ}$ and $\mathrm{CK} \mathrm{z}^{-}$ scores. Coaches may use modified sessions that allow for the players' position-specific intensity to be achieved with reduced volume thus allowing for the preservation of fitness levels with increased ability for players to recovery better post training and match play. Overall, the study suggests that coaches may try to alter players training load based on these pretraining assessments of readiness by increasing or reducing the players' load based on the Z-score analysis of pretraining assessments such as $\mathrm{CMJ}$ and $\mathrm{CK}$.

\section{REFERENCES}

1. Anderson, H, Raastad, T, Nilsson, J, Paulsen, G, Garthe, I, and Kadi, F. Neuromuscular fatigue and recovery in elite female soccer: effects of active recovery. Med Sci Sports Exer 40: 372-380, 2008.

2. Akenhead, E, Harley, J, and Tweddle, S. Examining the external training load of an English premier league football team with special reference to acceleration. J Strength Cond Res 30: 2424-2432, 2016

3. Batterham, AM and Hopkins, WG. Making meaningful inferences about magnitudes. Int J Sports Physiol Perform 1: 50-57, 2006.

4. Bush, M, Barnes, C, Archer, DT, Hogg, B, and Bradley, PS. Evolution of match performance parameters for various playing positions in the English premier league. Hum Mov Sci 39: 1-11, 2015.

5. Carling, C, Le Gall, F, and Dupont, G. Are physical performance and injury risk in a professional soccer team in match-play affected over a prolonged period of fixture congestion? Int J Sports Med 33: 36-42, 2012.

6. Cohen, J. Statistical Power Analysis for the Behavioural Sciences, Revised Ed. (xv 474). Hillsdale, NJ; England, United kingdom: Lawrence Erlbaum Associates, Inc. pp. 24, 1988.

7. Cormack, SJ, Newton, RU, and McGuigan, MR. Neuromuscular and endocrine responses of elite players to an Australian rules football match. Int J Sports Physiol Perform 3: 359-374, 2008.

8. Di Salvo, V, Baron, R, Tschan, H, Calderon Montero, FJ, Bachl, N, and Pigozzi, F. Performance characteristics according to playing position in elite soccer. Int J Sports Med 28: 222-227, 2007.

9. di Prampero, PE, Fusi, S, Sepulcri, L, Morin, JB, Belli, A, and Antonutto, G. Sprint running: a new energetic approach. J Exp Biol 208: 2809-2816, 2005

10. Duffield, R, Reid, M, Baker, J, and Spratford, W. Accuracy and reliability of GPS devices for measurement of movement patterns in confined spaces for court-based sports. J Sci Med Sport 13: 523-525, 2010

11. Foster, C, Florhaug, JA, Franklin, J, Gottschall, L, Hrovatin, LA, Parker, S, Doleshal, P, and Dodge, C. A new approach to monitoring exercise training. J Strength Cond Res 15: 109-115, 2001.

12. Gaudino, P, Iaia, FM, Alberti, G, Strudwick, AJ, Atkinson, G, and Gregson, W. Monitoring training in elite soccer players: systematic bias between running speed and metabolic power data. Int $J$ Sports Med 34: 963-968, 2013.

13. Gaudino, P, Iaia, FM, Alberti, G, Hawkins, RD, Strudwick, AJ, and Gregson, W. Systematic bias between running speed and metabolic power data in elite soccer players: influence of drill type. Int J Sports Med 35: 489-493, 2014.

14. Halson, SL and Jeukendrup, AE. Does overtraining exist? an analysis of overreaching and overtraining research. Sports Med 34: 967-981, 2004.

15. Hopkins, WG, Marshall, SW, Batterham, AM, and Hanin, J. Progressive statistics for studies in sports medicine and exercise science. Med Sci Sports Exerc 41: 3-13, 2009. 
16. Johnston, RD, Gabbett, TJ, Jenkins, DG, and Hulin, BT. Influence of physical qualities on post-match fatigue in rugby league. J Sci Med Sport 18: 209-213, 2015.

17. Jones, MR, West, DJ, Harrington, BJ, Cook, CJ, Bracken, RM, Shearer, DA, and Kilduff, LP. Match play performance characteristics that predict post-match creatine kinase responses in professional rugby union players. BMC 6: 38, 2014.

18. Kraemer, WJ, Spiering, BA, Volek, JS, Martin, GJ, Howard, RL, Ratamess, NA, Hatfield, DL, Vingren, JL, Ho, JY, Fragala, MS, Thomas, GA, French, DN, Anderson, JM, Hakkinen, K, and Maresh, $\mathrm{CM}$. Recovery from a national collegiate athletic association division 1 football game: muscle damage and hormonal status. $J$ Strength Cond Res 23: 2-10, 2009.

19. Meister, S, Der Funten, K, and Meyer, T. Repeated monitoring of blood parameters for evaluating strain and overload in elite professional players: is it justified? J Sports Sci 32: 1328-1331, 2014.

20. Malone, JJ, Di Michele, R, Morgans, R, Burgess, D, Morton, JP, and Drust, B. Seasonal training-load quantification in elite English premier league soccer players. Int J Sports Physiol Perform 10: 489-497, 2015.

21. Malone, S, Owen, A, Newton, M, Mendes, B, Collins, KD, and Gabbett, TJ. The acute:chronic workload ratio in relation to injury risk in professional soccer. J Sci Med Sport 20: 561-565, 2016.

22. Nedelec, M, McCall, A, Carling, C, Legall, F, Berthoin, B, and Dupont, G. Recovery in soccer: part II-recovery strategies. Sports Med 43: 9-22, 2013.

23. Nedelec, M, McCall, A, Carling, C, Legall, F, Berthoin, S, and Dupont, $\mathrm{G}$. The influence of soccer playing actions on the recovery kinetics after a soccer match. J Strength Cond Res 28: 1517-1523, 2014.

24. Osgnach, C, Poser, S, Bernardini, R, Rinaldo, R, and di Prampero, PE. Energy cost and metabolic power in elite soccer: a new match analysis approach. Med Sci Sports Exer 42: 170-178, 2010.

25. Owen, A, Dunlop, G, Rouissi, M, Chtara, M, Paul, D, Zouhal, H, and Wong, DP. The relationship between lower-limb strength and match-related muscle damage in elite level professional European soccer players. J Sports Sci 33: 2100-2105, 2015.
26. Peat, J and Barton, B. Medical Statistics: A Guide to Data Analysis and Critical Appraisal. Oxford, United kingdom: John Wiley \& Sons, 2008.

27. Ra, SG, Maeda, S, Higashino, R, Imai, T, and Miyakawa, S. Metabolomics of salivary fatigue markers in soccer players after consecutive games. J Appl Physiol Nutr Met 39: 1120-1126, 2014.

28. Rampinini, E, Impellizzeri, FM, Castagna, C, Coutts, AJ, and Wisloff, U. Technical performance during soccer matches of the Italian Serie a league: effect of fatigue and competitive level. J Sci Med Sport 12: 227-233, 2009.

29. Reilly, T. The training process. In: The Science of Training-Soccer: A Scientific Approach to Developing Strength, Speed and Endurance. Reilly, T, ed. London, United Kingdom: Routledge. pp. 1-19, 2007.

30. Rollo, I, Impellizzeri, FM, Zago, M, and Iaia, FM. Effects of 1 versus 2 games a week on physical and subjective scores of sub-elite soccer players. Int J Sports Physiol Perform 9: 425-431, 2014.

31. Russell, M, Sparkes, W, Northeast, J, Cook, CJ, Love, TD, Bracken, RM, and Kilduff, LP. Changes in acceleration and deceleration capacity throughout professional soccer match play. J Strength Cond Res 30: 2839-2844, 2016.

32. Russell, M, Sparkes, W, Northeast, J, Cook, CJ, Bracken, RM, and Kilduff, LP. Relationships between match activities and peak power output and creatine kinase responses to professional reserve team soccer match-play. Hum Mov Sci 45: 95-101, 2016.

33. Thorpe, $\mathrm{R}$ and Sunderland, C. Muscle damage, endocrine and immune marker response to a soccer match. J Strength Cond Res 26: 2783-2790, 2012.

34. Twist, C, Waldron, M, Highton, J, Burt, D, and Daniels, M. Neuromuscular, biochemical and perceptual post-match fatigue in professional rugby league forwards and backs. J Sports Sci 30: 359367, 2012.

35. Varley, MC and Aughey, RJ. Acceleration profiles in elite Australian soccer. Int J Sports Med 34: 34-39, 2013.

36. Young, WB, Hepner, J, and Robbins, DW. Movement demands in Australian rules football as indicators of muscle damage. J Strength Cond Res 26: 492-496, 2012. 